\title{
Effect of Voice Reinforcement Method for Treatment of Vocal Nodules: Preliminary Study
}

\author{
Ji-Sung Kim¹ (iD, and Dong-Wook Lee ${ }^{\text {(DD }}$ \\ 'Department of Otorhinolaryngology, Chungbuk National University Hospital, Cheongju, Korea \\ 2Department of Otorhinolaryngology-Head and Neck Surgery, Chungbuk National University College of Medicine, Cheongju, Korea
}

음성강화기법의 성대결절 치료 효과

김지성 1 , 이동욱 2

충북대학교병원 이비인후과 음성언어치료실, ${ }^{1}$ 충북대학교 의과대학 이비인후-두경부외과학교실2

Background and Objective The purpose of this study is to report the effect of voice therapy using the voice reinforcement method (VRM) in patients with vocal nodules. It is one of the holistic voice therapy methods for improving vocal mechanisms. VRM includes not only direct and indirect voice therapy, but also trial therapy and self-practice. Composed of four stages: vocal hygiene education, relaxation, reinforcement, and generalization.

Materials and Methods The subjects were 13 patients who were diagnosed with vocal nodules. Acoustic analysis, auditory perceptual assessment, K-VHI-10 and nodules size were compared before and after voice therapy. Voice therapy was conducted by speech-language pathologist and the mean number was 4.2 .

Results In acoustic analysis, Jitter, $\mathrm{vF}_{0}, \mathrm{VAm}$, Shimmer, NHR, and VTI were significantly decreased. $F_{0}$ was increased after voice therapy for women. 'Grade', 'Rough,' and 'Breathy' were significantly decreased in the GRBAS scale after voice therapy. In addition, $\mathrm{K}-\mathrm{VHI}-10$ and nodules size were significantly decreased.

Conclusion VRM seems to be an effective voice therapy method in vocal nodules treatment. In VRM, especially, trial therapy is given motivation for vocal nodules treatments and self-practice has a continuous therapeutic effect in everyday life. VRM can be also applied to the voice therapy for other hyper-functional dysphonia.

Keywords Vocal nodules; Voice therapy; Semi-occluded vocal tract exercise.

\section{서 론}

우리가 말소리를 이해하기 위해서는 가장 먼저 고막이 진동되어야 하듯이 말소리가 산출되기 위해서는 성대가 진동되어야 한다. 성대의 개폐에 따른 진동은 폐로부터 나오 는 공기의 흐름(air stream)과 성대 근육의 탄성도(elasticity) 및 긴장도(tension)에 의 해 시작되고 변화된다. 성대는 조직학적 측면에서 상피층(epithelium), 고유층(lamina propria), 근육층(vocalis muscle)으로 나누며, 고유층은 다시 표층(superficial layer, Reinke's space), 중간층(intermediate layer), 심층(deep layer)으로 구분한다. 또한, 상

\author{
Received April 13, 2020 \\ Revised May 7, 2020 \\ Accepted May 25, 2020

\section{Corresponding Author} \\ Dong-Wook Lee, MD \\ Department of Otorhinolaryngology- \\ Head and Neck Surgery, \\ Chungbuk National University, \\ College of Medicine, \\ 776 1sunhwan-ro, \\ Cheongju 28644, Korea \\ Tel +82-43-269-6150 \\ Fax+82-43-269-6609 \\ E-mail dwlee@chungbuk.ac.kr
}

\section{ORCID iDs}

Ji-Sung Kim (D)

https://orcid.org/0000-0003-2363-5060

Dong-Wook Lee (D)

https://orcid.org/0000-0002-3333-6083

This is an Open Access article distributed under the terms of the Creative Commons Attribution Non-Commercial License (https://creativecommons.org/ licenses/by-nc/4.0) which permits unrestricted non-commercial use, distribution, and reproduction in any medium, provided the original work is properly cited. 
피층과 고유층 사이에는 성대 기저막 영역(basement membrane zone)이 존재한다. 기저막 영역은 성대 점막운동에 관 여하여 고도의 성대진동과 파동운동에서 성대의 상피층과 고유층의 표층이 분리되지 않도록 연결하는 구조물이다. 성 대 진동 시 가장 심하게 진동하며 라인케 공간이라고 불리는 고유층의 표층과 기저막 영역은 성대점막 파동에 의한 가장 많은 에너지가 전달되는 부분으로 성대에서 발생하는 대부 분의 병변이 나타나는 조직이다. ${ }^{1)}$

성대결절은 음성오남용에서 비롯된 음성외상(phonotrau$\mathrm{ma}$ )으로 고유층의 손상 없이 기저막의 반복된 손상에 의해 발생 된다. 만성적인 음성외상은 성대의 상피 세포 사이의 연 결(desmosome)과 기저막과 상피기저세포 사이의 연결(hemi-desmosome)을 파괴하고, 이로 인해 두 조직이 분리되고 국소적인 세포액의 침착이 일어나게 된다. 이후 치료과정에 서 기저막이 생성되기 전 또다른 음성외상이 가해지면 기저 막은 재형성되지 못하고 성대 상피 세포층과 기저막 틈이 두 꺼워져 성대결절이 형성되는 것이다. ${ }^{2}$ 결절이 있는 성대는 정 상성대에 비해 성문폐쇄(glottal closure)가 충분하지 못하고, 점막파동(mucosal wave)이 더 적고 성대 가장자리(vocal fold edge)에 국한되며 비대칭(asymmetry)적인 성대진동 양 상을 보인다. 또한, 이러한 불충분한 성대접촉을 보완하기 위 해 과도한 보상적 발성이 형성되어 음성문제가 더 심화될 수 있다. ${ }^{3)}$

성대결절의 치료 방법으로는 음성치료, 약물치료, 성대 내 주입술, 후두미세술등이 있으며, 이중 음성치료는 음성회복 과 성대 종물의 소실을 가져올 뿐만 아니라 성대의 진동외상 을 유발하는 음성오남용과 발성패턴을 수정하는 비침습적인 치료방법이다. 음성치료는 크게 음성장애 환자에게 후두의 구조와 기능을 인식시키고 음성위생법을 준수하도록 하는 간접치료와 특정한 방법을 통해 성대의 병리적인 상태와 음 질을 개선하며, 잘못된 발성습관을 수정하고 음성의 효율성 을 증가시키는 직접적인 치료로 구분할 수 있다. 대표적인 음성치료법에는 공명음성치료기법, 성대기능훈련, 엑센트 기 법, 반폐쇄성도운동(semi-occluded vocal tract exercise, SOVTE), 25가지 음성촉진기법이 있다.5) 이와 같은 방법들은 성대결절을 포함한 과기능적 발성장애에 효과적이라고 보고 되었으며, 국내외에서 이와 같은 치료방법들을 조합하거나 수정 및 보완한 음성치료법에 대한 연구가 이루어져왔다.6-11) 이중 반폐쇄성도운동을 이용한 음성치료는 성대결절뿐만 아 니라 성대폴립, 근긴장성발성장애와 같은 과기능적 발성장애 와 기능적 실성증과 같은 과소기능적 발성장애에서도 효과 적인 음성치료방법으로 보고되었다.9.12) 하지만, 성도의 반폐 쇄가 없는 일반적인 의사소통 상황에서의 음성사용을 위한
일반화 단계는 제시하지 못하였다. 이와 같은 SOVTE의 한 계를 개선하기 위해 본 연구자는 Boone의 25가지 음성 촉진 법 중 이완, 후두마사지, 음성배치법과 SOVTE 중 물저항빨 대발성과 허밍 발성을 조합한 음성강화기법(voice reinforcement method, VRM)을 고안하였다.59) 음성강화기법은 음성산출 메커니즘을 강화하는 총체적 음성치료법으로, 간 접치료인 음성위생교육 단계와 직접치료인 이완 단계, 호흡발 성강화 단계, 일반화 단계로 구성되어있다. 이에 따라 본 연 구는 성대결절 환자를 대상으로 음성치료를 실시하고 치료 전과 후의 음성을 비교하여 음성강화기법의 성대결절 치료 효과를 알아보고자 한다.

\section{대상 및 방법}

\section{연구 대상}

본 연구의 대상자는 2017년 1월부터 2018년 12월까지 음성 문제를 호소로 충북대학교병원 이비인후과를 내원하여 전문 의로부터 성대 결절로 진단을 받은 환자이다. 대상자들은 남성 2 명과 여성 11명으로 총 13명이며, 평균연령은 $39 \pm 16.07$ 세로 인후두역류질환과 호흡기 질환이 없고 난청과 신경학적 문제 가 없었다. 대상자 중 직업적 음성사용자는 5 명, 음성사용이 많 은 비직업적 음성사용자는 3 명이었으며 보컬이나 연기 전공의 예능계열 입시 준비생이 2명이었다. 음성평가 세션을 제외한 음성치료 횟수는 4.2회이었으며 음성치료기간은 평균 26.4일 이었다.

\section{음향학적 분석}

음성치료 전후 소음이 통제된 조용한 검사실에서 환자의 음성을 녹음하였다. 환자로 하여금 마이크와 입 사이 약 $10 \mathrm{~cm}$ 의 거리를 두고 편안한 음도와 강도에서 모음 /a/를 연장발성 하도록 하였으며, 13 명의 환자로부터 음성치료 전과 후 총 26개 의 음성자료를 얻어냈다. /a/연장 발성 중 안정구간 1 초를 선택 하여 Kay PENTAX사에서 개발한 Multi-speech 3.7 (KayPENTAX Elemetrics, Lincoln Park, NJ, USA)의 multidimensional voice program(MDVP)을 이용하여 기본주파수 관련 변수 Average Fundamental Frequency $\left(\mathrm{F}_{0}\right)$, Jitter Percent(Jitter), Fundamental Frequency Variation $\left(\mathrm{VF}_{\mathrm{F}}\right)$ 와 음성 강도 관련변수 Shimmer Percent(Shimmer), Peak to Peak Amplitude Variation(vAm), 진전 관련변수 Fo Tremor Intensity Index(FTRI), Amplitude Tremor Intensity Index(ATRI), 잡음관련변수 Noise to Harmonic Ratio(NHR), Voice Turbulence Index(VTI)를 분석하여 음향학적 차이를 확인하였다. 


\section{청지각적 평가}

본 연구자는 음성치료 전후 /a/ 모음연장발성을 듣고 GRBAS 척도로 청지각적 평가를 실시하였다. 각각의 척도는 기존의 GRBAS와는 다르게 0 4점 $(0=$ 문제없음, $1=$ 문제라고 보기 어려운 수준, 대화수준에서 청지각적 음질 문제 없음, $2=$ 경도, $3=$ 중도, $4=$ 심도)으로 평가하였다. 청지각적 평가의 신 뢰도 확인을 위해 이비인후과 음성장애 임상경험 6년 이상인 1 급언어재활사 2 명이 무작위로 수집되어 배치된 녹음자료를 듣고 각각 청지각적 평정을 실시하였다. 검사자 간의 신뢰도는 무작위로 추출한 $20 \%$ 를 평가한 결과, $96 \%, 96 \%, 96 \%, 100 \%$, $100 \%$ 였다. 두 검사자 간 GRBAS 점수가 일치하지 않는 경우 는 두 검사자가 동시에 같이 듣고 최종적으로 동의한 점수를 최종 측정치로 하였다.

\section{주관적인 음성장애 지수}

Voice Handicap Index(VHI)는 환자가 느끼는 주관적인 음성 상태를 평가하기 위한 것으로 후두적출 환자를 포함하 여 음성장애의 종류에 관계없이 음성장애 환자를 대상으로 광범위하게 사용되는 환자중심의 주관적인 음성평가 방법이 다. $\mathrm{VHI}$ 는 중재 전후의 비교나 음성장애 환자의 삶의 질을 알아보기 위한 설문으로 사용되어 왔다. 본 연구에서는 음성 치료 전과 후의 주관적인 음성장애를 비교하기 위해 임상에 서 시간경제성 및 효용성이 우수한 한국판 $\mathrm{K}-\mathrm{VHI}-10$ 을 사 용 하였다. ${ }^{13}$

\section{성대 점막 종물 크기 평가}

성대 점막의 종물 크기 평가는 후두내시경 검사를 통해 이비인후과 전문의가 4점 척도로 평가하였다. 평가 기준은 ' $0=$ clear, $1=\operatorname{tiny}$ (성대표면이 매끈하지 않음, 종물 형태가 명 확하게 드러나지 않음), $2=\operatorname{small}($ 종물 형태가 명확하고 크기 가 성대의 $1 / 3$ 미만), $3=$ moderate or more(종물 형태가 성대 의 $1 / 3$ 이상)이다.

\section{음성강화기법}

음성강화기법은 Boone의 25가지 음성 촉진법 중 이완, 후 두마사지, 음성배치법과 SOVTE 중 물저항빨대발성과 허밍 발성을 조합한 것으로 음성산출 메커니즘을 강화하는 총체 적인 음성치료법이다. 간접치료인 음성위생교육 단계와 직접 치료인 이완 단계, 호흡발성강화 단계, 일반화 단계로 구성되 어있다. 음성위생교육단계에서는 음성평가결과를 토대로 환 자의 음성문제에 대한 설명과 후두의 구조와 기능을 설명한 다. 이와 함께, 음성외상의 원인이 되는 음성의 오용과 남용 을 확인하여 맞춤용 음성위생을 제시하고, 물저항빨대발성
을 이용한 시도치료(trial therapy)를 실시한다. 이완단계에서 는 후두마사지와 경부운동을 통해 발성기관을 이완한다. 강 화단계는 음성효율성 증가를 목적으로 복식호흡 패턴 훈련 과 함께 물저항빨대발성, 허밍을 이용한 호흡-발성간의 협응 을 강화한다. 또한, 자가훈련을 위한 교육을 실시한다. 마지막 으로 일반화 단계에서는 음성배치를 통해 발성의 초점을 안 면으로 이동시키고 전방화된 발성의 초점을 지각하며 단어 와 문장수준, 자동구어와 대화수준으로 일반화한다. 자가훈련 은 치료실 밖 일상에서 환자가 스스로 수행하는 것으로 1 회 90 초가 소요되는 강화단계의 물저항빨대발성을 최소 하루 6 회 이상 하도록 한다. 음성위생교육단계부터 이완단계까지 는 간편과제인 편안한 음도의 연장발성을 실시하며 강화단계 후부터 종결까지는 다양한 음도에서의 연장발성, 글라이딩, 노래(생일축하노래)등 다양한 과제로 물저항빨대발성을 실시한다(Table 1).

\section{통계 분석}

수집한 자료를 통해 음성치료 전후의 음향학적 특성, 청지 각적 음성, 성대의 종물 크기와 주관적인 음성장애를 비교하 기 위해 Statistics Package for the Social Science(SPSS, version 21.0; IBM Corp., Armonk, NY, USA)를 이용하여 Wilcoxon's signed-ranks test를 실시하였으며, 95\% 수준에서 유 의성을 검증하였다.

\section{결 과}

\section{음성치료 전후의 음향학적 분석결과 비교}

Table 2에 나타난 바와 같이 음성치료 전과 후의 음성을 음향학적으로 분석한 결과 $\mathrm{F}_{0}(\mathrm{p}=0.008), \operatorname{Jitter}(\mathrm{p}=0.001)$, $\mathrm{vF}_{0}(\mathrm{p}=0.006)$, Shimmer(p=0.001), $v \mathrm{Am}(\mathrm{p}=0.003), \operatorname{NHR}(\mathrm{p}=$ 0.002), $\operatorname{VTI}(\mathrm{p}=0.006), \operatorname{FTRI}(\mathrm{p}=0.009), \operatorname{ATRI}(\mathrm{p}=0.019)$ 에서 모두 유의한 차이를 보였다. $\mathrm{F}_{0}$ (Average Fundamental Frequency)는 성별에 따른 차이를 고려하여 여성 대상자의 결과 만을 비교한 결과, 치료 전 $178.9 \mathrm{~Hz}$ 에서 치료 후 $200.05 \mathrm{~Hz}$ 로 증가하였다. 주파수변동률(Jitter)에서는 치료 전 2.375\%에서 치료 후 $0.555 \%$ 로, $\mathrm{vF}_{0}$ (Fundamental Frequency Variation, 기본주파수 변이)은 $3.532 \%$ 에서 $0.842 \%$ 로 감소하였다. 강도 변동률(Shimmer)은 $11.932 \%$ 에서 $4.097 \%$ 로, vAm(peak to Peak Amplitude Variation, 강도변이)는 $18.347 \%$ 에서 $7.402 \%$ 로 감소하였다. 비정상배음의 비율을 반영하여 음성 의 전반적 잡음을 설명하는 noise to harmonic ratio(NHR, 잡음대 배음비)은 치료 전 0.245 에서 치료 후 0.135로, $\operatorname{VTI(ㄱㅗ~}$ 주파 잡음대 소음비)에서도 치료 전 0.068 에서 치료 후 0.048 
Table 1. Protocol of Voice Reinforcement Method

\begin{tabular}{|c|c|c|}
\hline Stage & Content & Reference \\
\hline \multirow[t]{5}{*}{ I Vocal hygiene-education } & Counseling (explanation of problem) & Boone et al..$^{5)}$ \\
\hline & Elimination of vocal misuse \& abuse & Boone et al..$^{5}$ \\
\hline & Customized vocal hygiene & \\
\hline & trial therapy (water-resistance straw phonation*) & Kim et al..$^{9)}$ \\
\hline & -simple task: sustained phonation & \\
\hline \multirow[t]{2}{*}{ II Relaxation } & Laryngeal massage & Kim et al. ${ }^{9)}$ \\
\hline & Neck \& shoulder stretching & \\
\hline \multirow[t]{4}{*}{ III Reinforcement } & Abdominal respiration & Boone et al. ${ }^{5)}$ \\
\hline & Humming & Kim et al. ${ }^{9)}$ \\
\hline & Water-resistance straw phonation* & Kim et al..$^{9,16)}$ \\
\hline & -multiple task (sustained, gliding, singing) & Chae et al. ${ }^{12)}$ \\
\hline IV Generalization & Voice focus & Boone et al.5) \\
\hline
\end{tabular}

*Self practice continues until the end of voice therapy (simple task: stage II, multiple tasks: stage III-IV)

Table 2. Comparison of acoustic measures before and after voice therapy

$\begin{array}{lccc} & \text { Before } & \text { After } & \text { Z } \\ \mathrm{F}_{0} & 178.9(31.12) & 200.05(23.4) & -2.667^{* *} \\ \text { Jitter } & 2.375(2.63) & 0.555(0.26) & -3.180^{* * *} \\ \text { vF }_{0} & 3.532(5.69) & 0.842(0.31) & -2.760^{* *} \\ \text { Shimmer } & 11.932(7.76) & 4.097(1.33) & -3.180^{* * *} \\ \text { vAm } & 18.347(10.61) & 7.402(3.11) & -2.970^{* *} \\ \text { NHR } & 0.245(0.17) & 0.135(0.01) & -3.111^{* *} \\ \text { VTI } & 0.068(0.02) & 0.048(0.02) & -2.760^{* *}\end{array}$

Data are presented as mean ( \pm standard deviation). ${ }^{* *} \mathrm{p} \leq 0.01$, ${ }^{* * *} \mathrm{p} \leq 0.001$

로 감소하였다.

\section{음성치료 전후의 주관적인 음성장애와 청지각적}

평가 및 성대 종물 크기 척도 결과 비교

음성치료 전과 후의 청지각적 평가결과 Table 3에 나타난 바와 같이 Grade $(\mathrm{p}=0.001)$, Rough $(\mathrm{p}=0.034)$, Breathy $(\mathrm{p}=$ 0.002)에서 유의한 차이가 나타났다. Grade 척도는 치료 전 2.462에서 치료 후 0.358로, Rough 척도는 치료 전 0.846에 서 치료 후 0 으로, Breathy 척도는 치료 전 1.846에서 치료 후 0.231로 감소하였다. Asthenic, strained은 치료 전후 동일 하게 0이었다. 또한, 성대 종물 크기 척도와 VHI-10 점수 역 시 치료 전과 후 유의한 차이가 나타났다 $(\mathrm{p}=0.002)$. 성대 종 물 크기 척도는 치료 전 2.000에서 치료 후 0.384 로 VHI-10 은 16.154점에서 5.846점으로 감소하였다.
Table 3. Comparisons of auditory-perceptual measures, $\mathrm{K}-\mathrm{VHI}-10$ and Grade of vocal mass size before and after voice therapy

\begin{tabular}{lccc} 
& Before & After & Z \\
Grade & $2.462(0.66)$ & $0.358(0.66)$ & $-3.219^{* * *}$ \\
Rough & $0.846(1.14)$ & 0 & $-2.121^{*}$ \\
Breathy & $1.846(0.99)$ & $0.231(0.66)$ & $-3.006^{* *}$ \\
VHI-10 & $16.154(7.26)$ & $5.846(5.05)$ & $-3.062^{* *}$ \\
Mass size-grade & $2.000(0.707)$ & $0.384(0.506)$ & $-3.066^{* *}$ \\
\hline
\end{tabular}

Data are presented as mean ( \pm standard deviation). ${ }^{*} \mathrm{p} \leq 0.05$, ${ }^{* *} \mathrm{p} \leq 0.01,{ }^{* * *} \mathrm{p} \leq 0.001$

\section{고 찰}

본 연구는 성대결절 환자를 대상으로 음성강화기법(VRM) 의 음성치료 효과를 알아보기 위한 것이다. 이를 위해, 음성치 료 전과 후의 음성을 비교하였다. 음성측정은 MDVP를 이용 한 음향학적 검사, VHI-10을 이용한 주관적인 음성장애 평 가와 GRBAS 검사를 이용한 청지각적 평가를 실시하였다. 또 한, 후두내시경 검사를 통해 성대결절의 크기변화를 살펴보 았다. 치료 후 음향학적 검사에서 음도와 강도의 주기성을 나 타내는 Jitter와 Shimmer, 음도와 강도의 변이를 나타내는 $\mathrm{vF}_{0}$ 와 $\mathrm{vAm}$ 가 정상범위 수준으로 감소하였다. 음성의 전반적 잡 음을 설명하며 비정상배음의 비율을 나타내는 NHR과 성대 폐쇄의 불완전성을 반영하는 VTI 역시 정상범위 수준으로 감 소한 것으로 나타났다. 남성 대상자 2 명을 제외한 여성 대상자 10 명의 기본주파수는 $178.9 \mathrm{~Hz}$ 에서 $200.05 \mathrm{~Hz}$ 로 치료 후 증 가하였다. GRBAS 척도를 사용한 청지각적 평가에서는 치료 후 중증도 $(\mathrm{G})$, 조조성 $(\mathrm{R})$, 기식성 $(\mathrm{B})$ 이 1.0 이하로 감소하였으 며, 주관적인 음성장애를 나타내는 K-VHI-10도 치료 후 16점 
에서 5.8점으로 정상 범위인 11점 이하 ${ }^{14}$ 로 감소를 나타내었 다. 또한, 치료 전과 후 성대 점막의 종물 크기 척도 역시 small 수준인 2.0에서 0.384 로 감소하였다. 이러한 결과는 음성강화 기법이 성대결절 치료에 효과적인 방법임을 시사한다.

본 연구에서 음성치료기간은 평균 26.4일이었으며, 치료횟 수는 4.2회였다. 음성치료는 주 1 회로 정하여 시행되지는 않 았으며, 발성기관의 과긴장이 없는 경우에는 이완단계를 생 략하고 실시하였다. 음성위생교육단계는 음성평가시 이루어 졌으며, 음성평가 후 1 3일 이내에 이완단계를 실시하고 이 완단계 이후 2 3일 이내 강화단계를 실시하였다. 강화단계와 일반화단계는 한 회기에 진행되는 경우도 있었다. 치료진행 에 있어 환자에 따른 차이가 있었으나, 음성평가와 이완, 강 화단계를 짧은 기간 내에 실시하는 것을 원칙으로 하였다. 이와 같은 초기 집중치료를 통해 발성기관 이완과 음성산출 메커니즘을 강화시킨 후 음성배치를 이용한 대안적인 발성을 사용하도록 하여 일반화하였다.

강화단계의 물저항빨대발성은 음성강화법의 핵심적인 과 정이다. 물저항빨대발성은 성도의 앞을 좁히는 반폐쇄성도운 동 중 하나로 입 빨대를 물에 넣어 발성하는 것이다. 물저항 빨대발성시 좁은 빨대 직경을 통해 기류가 산출되기 때문에 성도의 앞이 반폐쇄된 조건이 된다. 성도가 반폐쇄되면 흡기 와 호기의 순환에 따라 산출되어야 할 호기류가 충분히 산 출되지 못해 구강의 압력이 증가되며, 성대 쪽으로 다시 되돌 아가는 역압(back pressure)이 증가된다. 이와 같은 역압의 증가로 인해 후두의 위치는 낮아지고 성문 사이의 틈이 발생 하며 성대진동시 진동충격이 감소한다. 성대진동시 개방구간 의 개방기가 짧은 것은 성대 점막의 경도(stiffness) 증가를 의미하는데, 물저항빨대발성시 성대진동의 개방기는 모음발 성보다 더 길게 나타난다. 이는 빨대발성시 성대 점막이 부드 러운 조건에서 진동함을 의미한다. ${ }^{15-17)}$ 이와 같은 원리에 의 해 물저항빨대발성은 발성시 진동충격을 감소시키고 성대진 동 패턴을 안정적으로 변화시켜 성대조직의 회복을 도울 뿐 아니라 증가된 구강압력을 견디고 발성하는 과정에서 흡기 근과 호기근의 저항운동을 촉진하기 때문에 음성산출을 위 한 호기량과 성문하압을 증가시켜 음성효율성을 높인다. 또 한, 물저항빨대발성시 물거품이 발생하여 즉각적으로 시각적 인 피드백을 제공할 수 있으며, 안면의 진동감이 지각되기 때 문에 일반화 단계에서 음성의 초점을 안면으로 전방화하는 음성배치를 쉽게 만드는 장점이 있다.

Kwon 등)은 음성위생, 이완, 엑센트 기법을 이용한 음성 치료법이 성대결절 환자의 음성개선에 효과적이라고 보고하 였으며, Kim과 Jeong근 문제인식, 웃음을 이용한 대안적 발성훈련, 근육이완과 호흡으로 구성된 음성치료법의 효과
를 보고하였다. $\operatorname{Lim}$ 등8)은 음성위생과 호흡훈련, 발성훈련, 활창훈련으로 구성된 성대기능훈련의 성대결절 치료효과를 보고하였다. 음성강화법은 이같이 음성위생과 같은 간접적인 음성치료와 이완, 대안적인 발성사용과 같은 직접적인 음성 치료를 포함하고 있다는 점에서 선행연구들과 공통점이 있 지만 음성평가 이후 시도치료를 실시하고 치료 종료까지 자 가훈련을 실시한다는 점에서는 구별된다.

$\mathrm{Kim}$ 등9)은 과기능적 발성장애로 진단 받은 대상자에게 음 성평가 이후 시도치료를 실시한 결과, 시도치료를 경험한 대 상자 중 음성치료를 거부한 경우는 없었다. 또한, 치료의 종결 은 대상자의 $83 \%$ 는 치료사의 기준에 따라, 나머지 $17 \%$ 는 음 성에 대한 개인의 주관적인 만족에 의해 이루어졌음을 보고 하며, 시도치료가 음성평가와 치료를 이어주는 가교 역할을 한다고 보고하였다. 본 연구에서도 음성평가 이후 문제의 설 명과 함께 실시한 시도치료는 다소 낮설게 느껴질 수 있는 음 성치료를 경험하고, 음성치료에 대한 신뢰형성과 동기 부여에 효과적인 방법이 될 수 있었다. $\mathrm{So}^{10)}$ 는 성대결절 아동을 대상 으로, $\mathrm{Kim}$ 등9)은 성대결절, 성대 폴립, 근긴장성 발성장애 환 자를 대상으로 빨대발성, 허밍, 입술 트릴과 같은 SOVTE의 음성치료효과를 보고하였으나, 성도의 반폐쇄가 없는 대화상 황을 위한 일반화 단계를 제시하지 못하였다. 음성강화법은 음성배치를 통해 일반화 단계를 제시함으로써 SOVTE를 이 용한 음성치료의 제한점을 보완했다는 점에서, 보다 완성도 높은 음성치료법이라 할 수 있겠다. Kang 등 ${ }^{18)}$ 은 시간에 따 른 물저항빨대발성의 효과변화를 알아보기 위해 물저항빨대 발성 실시 후 5 분 간격으로 최소발성역치(Phonation Threshold Pressure, PTP)를 측정하였다. 그 결과, 실시 후 5분, 10 분, 15 분, 20 분의 PTP는 실시전보다 낮았고, 실시 후 10 분 이후부 터 PTP는 다시 증가하였다. 이는 물저항빨대발성의 효과가 실 시 후 20 분까지는 지속될 수 있음을 시사한다. 음성강화법의 자가훈련은 성대의 진동충격을 감소시키고 성대진동 패턴을 안정적으로 변화시켜 성대조직의 회복을 돕고, 발성을 위한 호흡근의 저항운동을 촉진하여 발성의 효율성을 높이는 물저 항빨대발성의 장점이 치료실 밖 환자의 일상에서 환자의 성대 와 음성에 지속적으로 반영되기 때문에, 성대 점막의 회복과 음 성개선을 보다 효과적으로 가져오는 방법이라고 할 수 있겠다.

본 연구는 대조군이 없고 대상자 수가 적으며 음성측정에 있어 음향학적 검사와 청지각적 평가, 주관적인 음성장애, 성 대종물의 크기변화 여부만을 척도로 평가하였다는 제한점을 가진다. 추후 연구에서는 공기역학적 평가와 전기성문 파형 검사를 포함하고, 후두스트로보스코프나 초고속 비디오 후 두내시경을 이용하여 성대의 진동 양상의 변화를 살펴볼 필 요가 있겠다. 또한, 절대적 음성안정, 침습적인 치료, 다른 음 
성치료법과 비교하여 음성강화기법의 치료효과에 대한 객관 적인 연구가 필요하겠다. 최근 음성치료에 반응하지 않거나 치료참여가 어려운 음성장애 환자에서 후두미세술을 피할 수 있는 방법으로 성대 내 주입술의 유용성이 보고되고 있 다. ${ }^{19,20)}$ 추후 연구에서는 이와 같은 치료법의 발전에 따라 음 성위생교육과 음성오남용 제거 및 발성패턴 수정과 같은 전 통적인 방법의 행동적 음성치료뿐만 아니라 성대 내 주입술 의 보조적인 방법으로 주입물의 특성에 따라 성대의 진동을 촉진 시켜줄 수 있는 음성치료법에 대한 연구가 이루어질 필 요가 있겠다.

\section{결 론}

본 연구는 성대결절 환자를 대상으로 25가지 음성 촉진법 중 이완 및 후두마사지, 음성배치법과 SOVTE 중 물저항빨대 발성과 허밍 발성을 조합한 음성강화기법(VRM)을 적용한 음 성치료를 실시하였다. 그 결과, 결절의 크기가 감소하거나 소 실되었으며, 음향학적, 청지각적, 주관적 측면에서 음성의 개 선이 나타났다. 이를 통해, 음성위생교육과 같은 간접치료와 발성기관의 이완, 음성산출메커니즘의 강화 및 대안적인 발성 을 포함하는 직접적인 치료뿐 아니라 음성평가에서 시도치료 를 실시하고, 음성치료 기간 동안 자가훈련을 권고하는 음성 강화기법이 성대결절 치료에 효과적인 방법임을 확인할 수 있 었다.

중심 단어: 성대결절, 음성치료, 반폐쇄성도운동.

Acknowledgments

None.

\section{Conflicts of Interest}

The authors have no financial conflicts of interest.

\section{Authors' Contribution}

Conceptualization: Ji-Sung Kim. Data curation: Ji-Sung Kim. Formal analysis: Ji-Sung Kim. Investigation:Ji-Sung Kim. Methodology: JiSung Kim. Project administration: Dong-Wook Lee. Supervision: Dong-Wook Lee. Writing-original draft: Ji-Sung Kim. Writing-review \& editing: Ji-Sung Kim. Approval of final manuscript: all authors.

\section{REFERENCES}

1. Park LS. Anatomy for sound production. In: The Korean Society of Laryngology, Phoniatrics and Logopedics, editor. Laryngology, Phoniatrics and Logopedics I. 1st ed. Seoul: Ilchokak; 2012. p.40.
2. Kim HT, Chu YH, Choi HK, Kim HS, Cho SH. Pathogenetic hypothesis of benign laryangeal disease from histopathologic change in the basement membrane zone and the superficial layer of lamina propria. Korean J Otolaryngol-Head Neck Surg 2005;48(1):65-9.

3. Yamauchi A, Yokonishi H, Imagawa H, Sakakibara KI, Nito T, Tayama N, et al. Quantification of vocal fold vibration in various laryngeal disorders using high-speed digital imaging. J Voice 2016;30(2): 205-14.

4. Lee SH. Non-surgical management for benign vocal fold lesions. J Korean Soc Laryngol Phoniatr Logop 2015;26(2):97-100.

5. Boone DR, McFarlane SC, Von Berg SL, Zraick RI. The Voice and Voice Therapy. 8th ed. Boston, USA: Pearson Education Inc.;2010.

6. Kwon SB, Kim YJ, Jo CW, Jun KR, Lee BJ, Wang SG. The effect of accent method in treating vocal nodule patients. Korean J Speech Sciences 2001;8(4):87-98.

7. Kim ST, Jeong OR. The effects of SK-MVTT on voice improvement in vocal nodules patients; comparison with accent method. Korean J Speech Sciences 2004;11(4):101-20.

8. Lim HJ, Kim JK, Kwon DH, Park JY. The effect of vocal function exercise on voice improvement in patients with vocal nodules. J Korean Soc Speech Sci 2009;1(2):37-42.

9. Kim JS, Lee DW, Choi CH, Choi SH. Effects of laryngeal massage and semi-occluded vocal tract exercises for patients with hyperfunctional dysphonia. Commun Sci Disord 2017;22(4):806-17.

10. So YK. Efficacy of voice therapy for children with vocal nodules. J Clinical Otolaryngol 2018;29(2):229-34.

11. Allen MS, Pettit JM, Sherblom JC. Management of vocal nodules: a regional survey of otolaryngologists and speech-language pathologists. J Speech Hear Res 1991;34(2):229-35.

12. Chae HR, Kim JS, Lee DW, Choi SH. Effects of semi-occluded vocal tract exercise in patients with functional aphonia. J Korean Soc Laryngol Phoniatr Logoped 2019;30(1):48-52.

13. Yun YS, Kim HH, Son YI, Choi HS. Validation of the Korean Voice Handicap Index (K-VHI) and the clinical usefulness of Korean VHI-10. Commun Sci Disord 2008;13(2):216-41.

14. Arffa RE, Krishna P, Gartner-Schmidt J, Rosen CA. Normative values for the Voice Handicap Index-10. J Voice 2012;26(4):462-5.

15. Kim JS. Vocal fold vibration characteristics of the semi-occluded vocal tract exercise using vibration simulator [Doctor's thesis]. Gyeongsan: Daegu Catholic Univ.;2020.

16. Kim JS, Choi SH, Choi CH, Lee DW, Kim JS, Choi SH. Effect of voice rherapy for persistent dysphonia following laryngeal microsurgery. Communication Sciences \& Disorders 2019;24(2):525-34.

17. Titze IR. Voice training and therapy with a semi-occluded vocal tract: rationale and scientific underpinnings. J Speech Lang Hear Res 2006; 49(2):448-59.

18. Kang J, Xue C, Chou A, Scholp A, Gong T, Zhang Y, et al. Comparing the exposure-response relationships of physiological and traditional vocal warm-ups on aerodynamic and acoustic parameters in untrained singers. J Voice 2019;33(4):420-8.

19. Lee JY, Lee JH, Choi JI, Lee SH, Jin SM. Usefulness of voice therapy on vocal nodules in professional Voice Users Treated with Steroid Injection. Korean J Otorhinolaryngol-Head Neck Surg 2014;57 (1):32-7.

20. Mortensen M, Woo P. Office steroid injections of the larynx. Laryngoscope 2006;116(10):1735-9. 